\title{
PIBID: HISTÓRIAS EM QUADRINHOS NA AQUISIÇÃO DA COMPETÊNCIA LEITORA
}

\section{Laiane Caroline de Lima ${ }^{1}$ \\ Vera Lúcia Catoto Dias ${ }^{2}$ \\ Anamaria da Silva Martin Gáscon Oliveira ${ }^{3}$}

Resumo: Este trabalho é uma pesquisa inicial do Programa Institucional de Bolsa de Iniciação à Docência (PIBID), convênio firmado entre universidade comunitária e escola pública, para formação inicial de professores para a educação básica. O presente projeto tem como objetivo investigar o processo de aquisição da leitura, utilizando Histórias em Quadrinhos como um recurso estimulador. A pesquisa em educação do tipo estudo de caso etnográfico (ANDRÉ,2005), foi desenvolvida pela observação participante de duas bolsistas PIBID, em sala do terceiro ano do ensino fundamental de uma escola estadual, localizada no município de São José dos Campos, estado de São Paulo, no ano de 2014. A metodologia centrou-se inicialmente em pesquisa bibliográfica fundamentada em: Oliveira (2007), Vergueiro (2010) e Santos (2003) dentre outros, seguida de pesquisa de campo, para identificação das contribuições das histórias em Quadrinhos para a aquisição da competência leitora.

Palavras-chave: Alfabetização; Leitura; História em quadrinho.

\footnotetext{
1 Pedagogia/UNIVAP - Universidade do Vale do Paraíba, Brasil. E-mail: lalah.carol@hotmail.com.

2 Pedagogia/UNIVAP - Universidade do Vale do Paraíba, Brasil. E-mail: vcatoto@univap.br.

3 Pedagogia/UNIVAP - Universidade do Vale do Paraíba, Brasil. E-mail: gascon@univap.br.
} 